University of Wollongong

Research Online

Faculty of Engineering and Information

Faculty of Engineering and Information

Sciences - Papers: Part B

Sciences

2020

Design and Optimization of a Novel Dual-Port Linear Generator for Oceanic Wave Energy Conversion

Omar Farrok

Md Rabiul Islam

University of Wollongong, mrislam@uow.edu.au

Kashem M. Muttaqi

University of Wollongong, kashem@uow.edu.au

Danny Sutanto

University of Wollongong, soetanto@uow.edu.au

Jianguo Zhu

Follow this and additional works at: https://ro.uow.edu.au/eispapers1

Part of the Engineering Commons, and the Science and Technology Studies Commons

Research Online is the open access institutional repository for the University of Wollongong. For further information contact the UOW Library: research-pubs@uow.edu.au 


\title{
Design and Optimization of a Novel Dual-Port Linear Generator for Oceanic Wave Energy Conversion
}

\begin{abstract}
All the existing linear generators used for oceanic wave energy conversions are basically a single-port linear electrical generators (SPLEGs). The conventional SPLEG transfers electrical power to the load/grid discontinuously due to its working principle and the intermittent nature of oceanic waves. This paper proposes a new dual-port linear electrical generator (DPLEG) topology, which is capable to transfer electrical power with an adequate voltage even at zero vertical velocity of the oceanic wave. The analysis shows that the efficiency and the performance of the DPLEG depend greatly on the stator tooth design. For this reason, the proposed DPLEG is optimized using the genetic algorithm for successful operation. The shape optimization method is implemented to determine the stator tooth shape of the DPLEG. By optimizing the stator tooth shape, the force ripples of the proposed DPLEG is further reduced by $40.89 \%$. The analysis is carried out using multiphysics simulation and the electromagnetic performance is determined by the finite element analysis. Simulation results show that the shape optimization of the stator tooth not only minimizes the force ripples of the translator but also increases the power generation of the DPLEG. A laboratory prototype of the proposed DPLEG is built to test the concept of the proposed DPLEG topology. The experimental results verify its unique advantage by showing that it can generate an adequate voltage even at zero vertical velocity of the oceanic wave which cannot be achieved using the existing SPLEGs.
\end{abstract}

\section{Keywords}

novel, dual-port, design, linear, optimization, generator, oceanic, wave, conversion, energy

\section{Disciplines}

Engineering | Science and Technology Studies

\section{Publication Details}

O. Farrok, M. Islam, K. M. Muttaqi, D. Sutanto \& J. Zhu, "Design and Optimization of a Novel Dual-Port Linear Generator for Oceanic Wave Energy Conversion," IEEE Transactions on Industrial Electronics, vol. 67, (5) pp. 3409-3418, 2020. 


\title{
Design and Optimization of a Novel Dual- Port Linear Generator for Oceanic Wave Energy Conversion
}

\author{
Omar Farrok1, Member, IEEE, Md. Rabiul Islam², Senior Member, IEEE \\ Kashem M Muttaqi², Senior Member, IEEE, Danny Sutanto², Senior Member, IEEE \\ and Jianguo $\mathrm{Zhu}^{3}$, Senior Member, IEEE
}

\begin{abstract}
All the existing linear generators used for oceanic wave energy conversions are basically a singleport linear electrical generators (SPLEGs). The conventional SPLEG transfers electrical power to the load/grid discontinuously due to its working principle and the intermittent nature of oceanic waves. This paper proposes a new dual-port linear electrical generator (DPLEG) topology, which is capable to transfer electrical power with an adequate voltage even at zero vertical velocity of the oceanic wave. The analysis shows that the efficiency and the performance of the DPLEG depend greatly on the stator tooth design. For this reason, the proposed DPLEG is optimized using the genetic algorithm for successful operation. The shape optimization method is implemented to determine the stator tooth shape of the DPLEG. By optimizing the stator tooth shape, the force ripples of the proposed DPLEG is further reduced by $40.89 \%$. The analysis is carried out using multiphysics simulation and the electromagnetic performance is determined by the finite element analysis. Simulation results show that the shape optimization of the stator tooth not only minimizes the force ripples of the translator but also increases the power generation of the DPLEG. A laboratory prototype of the proposed DPLEG is built to test the concept of the proposed DPLEG topology. The experimental results verify its unique advantage by showing that it can generate an adequate voltage even at zero vertical velocity of the oceanic wave which cannot be achieved using the existing SPLEGs.
\end{abstract}

Index Terms- Dual-port linear generator, genetic algorithm, stator tooth shape optimization, wave energy conversion

Manuscript received December 1, 2018; revised February 17, 2019 and March 27, 2019; accepted May 21, 2019.

O. Farrok is with the Department of Electrical and Electronic Engineering, Ahsanullah University of Science \& Technology, Dhaka, Bangladesh, (e-mail: omarruet@gmail.com,omar.eee@aust.edu).

M. R. Islam, K. M. Muttaqi, and D. Sutanto are with the School of Electrical, Computer and Telecommunications Engineering, University of Wollongong, New South Wales 2522, Australia (e-mail: mrislam@uow.edu.au, kashem@uow.edu.au, soetanto@uow.edu.au)

J. G. Zhu is with the School of Electrical and Information Engineering, University of Sydney, New South Wales 2006, Australia (e-mails: jianguo.zhu@sydney.edu.au).

\section{INTRODUCTION}

$\mathrm{T}$ HE challenges of electrical power production from renewable energy resources (RERs) are not only on the conversion of solar [1] and wind [2], [3] energies but also on how to address the safety issue [4] for their reliable operation. The oceanic wave energy (OWE) has attracted significant attentions worldwide as one of the non-conventional RERs. The OWE is able to supply a remarkable part of the existing demand of electrical power [1]. The values of the global wave energy potential are described in details and tabulated in [5] for different amplitude and frequency of the oceanic wave.

Various OWE converters have been studied, and among them linear generators are found to be attractive due to their utilization of the direct-drive linear motion system [6]. The linear generator can also save cost and increase its effectiveness by avoiding the use of intermediate mechanical devices [7]. The permanent magnet linear generator (PMLG) can generate electricity directly from the sea wave when connected to a wave energy device. A linear primary permanent magnet Vernier machine system is described in [8] which is proposed for direct-drive OWE conversion.

Most of the research papers focus on the improvement [9] of the electrical power generation from OWE in various ways. A lightweight translator has been proposed in [10] to improve the dynamics of the linear generator. Another PMLG has been proposed in [11] to minimize the overall system mass. The internal design of a tubular PMLG has been discussed in [12] with a saltwater air-gap bearing surface integration between the buoy components of the proposed PMLG. A PMLG with variable air gap length has been proposed in [13] to avoid irreversible demagnetization [14] which happens in almost every PMLG. A high power density linear generator is proposed in [15] where the armature windings are placed in the translator.

Some recent research papers focus on optimization of these linear generators, such as the graphical optimization is presented in [16] for an iron-less and brush-less PMLG. The optimization of two tubular PMLGs for OWE conversion are presented in [17] by evolutionary algorithms. The design and 
optimization of a superconducting racetrack magnet for the rotor of a wind-farm generator is described in [18]. However, the shape optimization of the stator and translator as shown in [19] and [20] greatly affects and improves different electrical and magnetic parameters of the linear generator.

Formerly, the pole-shifting method was widely used in reducing the cogging force, but it may cause an unbalanced voltage due to the asymmetric arrangement of PMs [21]. At present, researchers use many existing techniques to reduce the cogging force, such as using skewed PMs [22], design of slot-less PMLGs [23], etc. For instance, a slot-less generator has low detent force, but the power density of this generator is much lower than that of the generator with slots. In other words, the size of a slot-less generator is larger than the generator with slots for generating the same amount of electrical power generation [23], [24]. On the other hand, the cogging force generates vibrations, which can affect the foundations and the supporting structure of the linear generators [25]. There are significant challenges to manage the stability, the lifetime, and the reliability of the OWE conversion while smoothing out the generated power supply to achieve the best use of the OWE [26].

An oscillating water column based OWE conversion plant equipped with a doubly fed induction generator is modeled and controlled in [27]. The way to provide convenient tradeoff between the high-power extraction and the viable electrical device rating are discussed in [28]. The translator weight of a PMLG is reduced in [29] by a split translator and an additional secondary stator. The resonant behavior of a direct driven linear generator is shown in [30] where the translator is connected to a submerged float and a buoy, which can independently move. Therefore, all the existing linear generators are single-port type so far, which are unable to generate electricity when the translator reaches either of the ends as shown in Fig. 1. To keep the stator of the linear generator stationary, it is usually placed inside an anchored structure of the wave energy devices and the translator is free to move.

In this paper, at first a dual-port linear electrical generator (DPLEG) is proposed, which is able to generate electricity despite of the zero vertical velocity of the translator. This feature is not possible in any of the existing single-port linear electrical generators (SPLEGs). The proposed DPLEG is compact in design and robust in construction. It is shown that, the physical tooth shape optimization of the stator of a linear generator can significantly decrease the force ripples and increase the electrical power generation. To overcome this, the stator tooth shape of the proposed DPLEG has been further optimized: i) to generate more electricity and ii) to minimize force ripples of the translator to prevent mechanical vibration or even failure. Therefore, the proposed DPLEG topology can minimize the cost since any type of linear generator can take advantage of this topology. The proposed DPLEG exhibits excellent features of OWE conversion by which it becomes an all-in-one package.
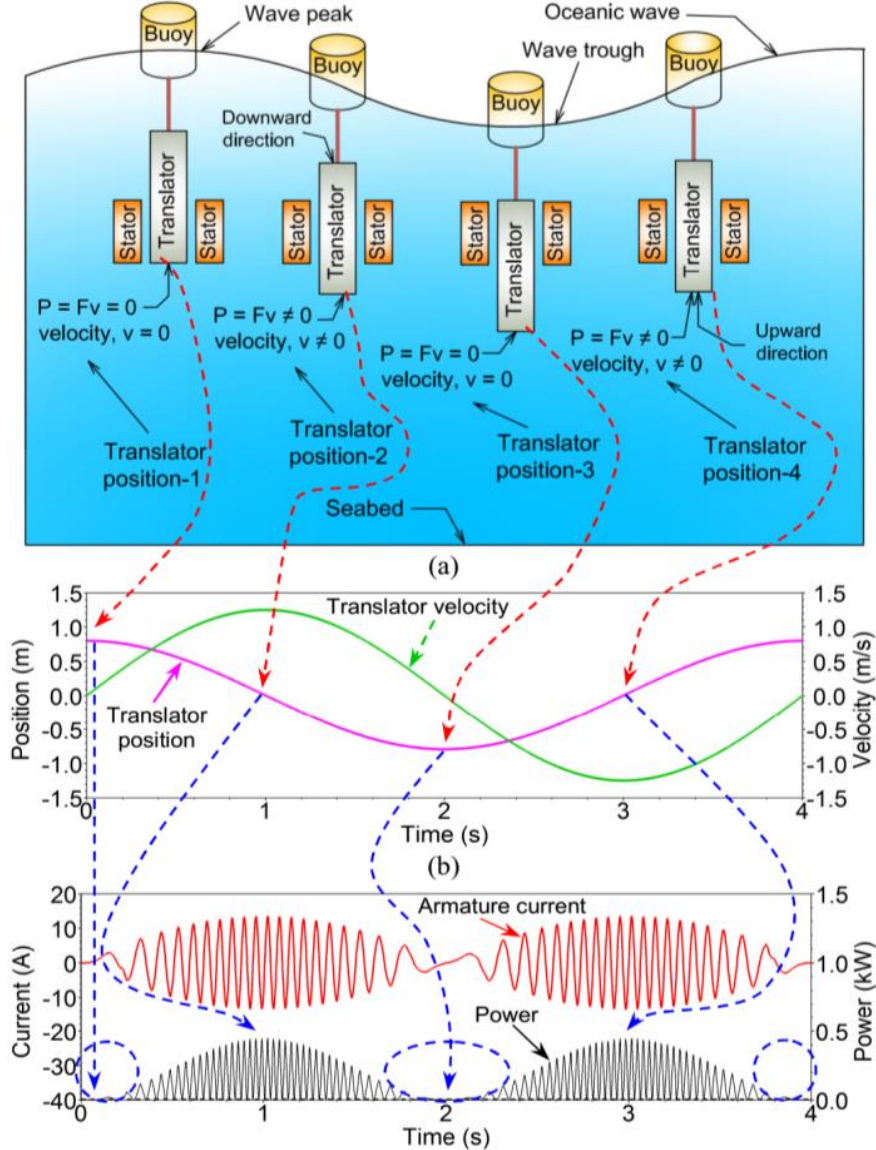

(c)

Fig. 1. Working principle of the existing single-port linear generator: (a) The arrangement used for oceanic wave energy extraction. (b) The position and velocity of the translator at different times. (c) The generated electrical power for different translator velocities for a full cycle of the OWE.

\section{Limitation OF THE Existing Single-PORT LiNEAR GENERATOR}

In most of the numerical analysis, the vertical motion of the translator of an existing SPLEG can be represented as:

$$
\begin{gathered}
z(t)=\mathrm{A}_{\max } \sin \left(\frac{2 \pi}{T} t \pm \alpha_{z}\right) \\
v(t)=\frac{2 \mathrm{~A}_{\max } \pi}{T} \cos \left(\frac{2 \pi}{T} t \pm \alpha_{v}\right)
\end{gathered}
$$

where $z(t)$ is the elevation, $v(t)$ the vertical velocity of the translator, $\mathrm{A}_{\max }$ the maximum magnitude of the translator, $\alpha$ the phase angle, and $T$ the time period.

The mechanical power, $P_{m}=F v$, obtained from the oceanic wave is converted to the electrical power, $P_{e}$ by means of a linear generator where $v$ is the velocity of the translator and $F$ the applied force. In the existing SPLEG, the translator's vertical speed is non-zero at translator positions 2 and 4 and zero at translator positions 1 and 3 as shown in Fig. 1. When $v=0$, the SPLEG does not generate electricity. The relations of the oceanic wave nature, translator position, velocity, armature current, and the electrical power generation are illustrated in Fig. 1. It is also clear that, the higher the 
translator's velocity, the higher the amplitude of the generated electrical power and vice-versa. The dashed enclosed area indicates that at translator positions 1 and 3 , the conventional SPLEG is unable to generate electricity.

\section{Model of the Proposed DuAl-Port Linear GENERATOR}

The proposed DPLEG consists of two different bodies of translator: the driver-translator and the driven-translator, as shown in Fig. 2. The float/buoy of the linear generator is direcly connected to the driver-translator only and the driventranslator is connected to the driver-translator through a mechanical spring.

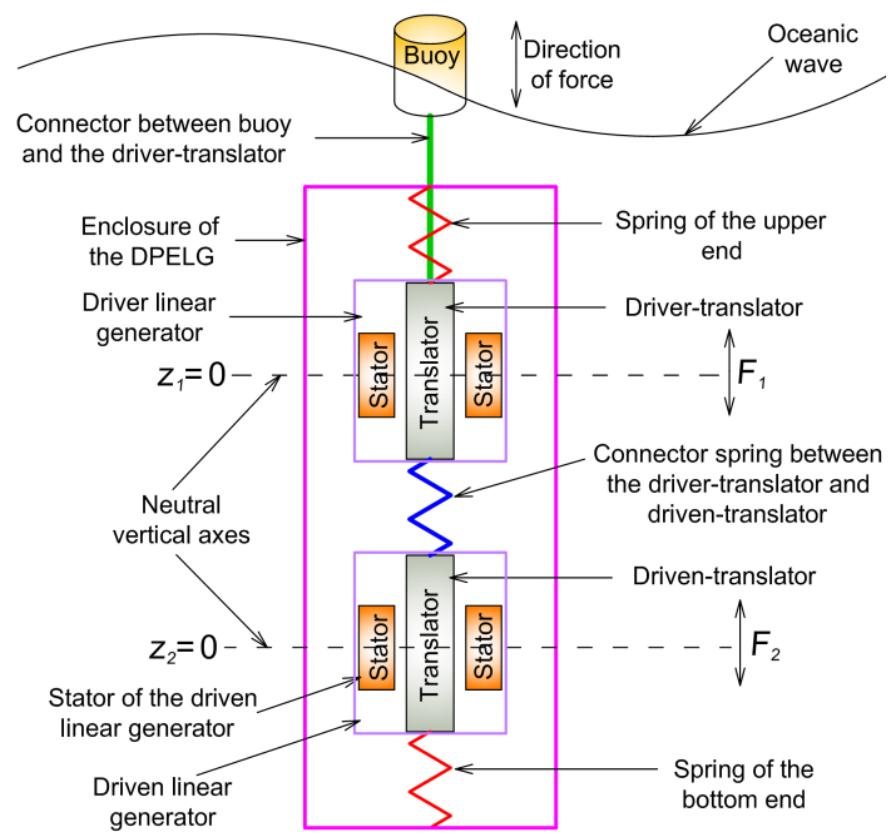

Fig. 2. Architecture of the proposed DPLEG.

By Newton's law, the motion of the driver and driventranslators in the linear direction can be expressed as:

$$
\begin{aligned}
& F_{d r v r}=-\left(k_{e}+k_{m}\right) z_{1}+k_{m} z_{2}=-\left\{k_{e} z_{1}-k_{m}\left(z_{2}-z_{1}\right)\right\} \\
& F_{d r v n}=-k_{m} z_{1}-\left(k_{e}+k_{m}\right) z_{2}=-\left\{k_{e} z_{2}+k_{m}\left(z_{2}-z_{1}\right)\right\}
\end{aligned}
$$

where $F_{d r v r}$ is the force applied to the driver-translator, $F_{d r v n}$ the force transferred to the driven-translator through the spring, $m$ the mass of each of the translators, $z_{l}$ the vertical displacement of the driver-translator, $z_{2}$ the vertical displacement of the driven-translator, $K_{e}$ the spring constant of the spring situated at the both ends, and $k_{m}$ the spring constant of the spring connecting the driver and driventranslator. The natural frequency, $\omega$ can be determined by solving the following equations which are obtained from (2):

$$
z(t)=\left[\begin{array}{l}
z_{1}(t) \\
z_{2}(t)
\end{array}\right]=\left[\begin{array}{l}
z_{1} \\
z_{2}
\end{array}\right] e^{-\mathrm{j} \omega \mathrm{t}}
$$

$$
\begin{gathered}
a(t)=\frac{d^{2}}{d t^{2}} z(t)=-\omega^{2}\left[\begin{array}{c}
z_{1} \\
z_{2}
\end{array}\right] e^{-\mathrm{j} \omega \mathrm{t}} \\
F(t)=\left[\begin{array}{cc}
-\left(k_{e}+k_{m}\right) & k_{m} \\
k_{m} & -\left(k_{e}+k_{m}\right)
\end{array}\right]\left[\begin{array}{l}
z_{1} \\
z_{2}
\end{array}\right] e^{-\mathrm{j} \omega \mathrm{t}}
\end{gathered}
$$

Solving (4) and (5), natural frequency can be obtained as:

$$
\omega=\sqrt{\frac{k_{e}}{m}}=\omega_{L}, \sqrt{\frac{k_{e}+2 k_{m}}{m}}=\omega_{H}
$$

where $\omega_{L}$ and $\omega_{H}$ are the minimum and the maximum values of the natural frequencies of the driver- and driven-translators, respectively, which mainly depend on the spring constants and the masses of the translators. The more generalized equations of motion can be expressed as:

$$
\begin{aligned}
& z_{1}(t)=\frac{1}{2}\left\{\mathrm{~A}_{\mathrm{L}} \cos \left(\omega_{L} t+\varphi_{L}\right)+\mathrm{A}_{\mathrm{H}} \cos \left(\omega_{H} t+\varphi_{H}\right)\right\} \\
& z_{2}(t)=\frac{1}{2}\left\{\mathrm{~A}_{\mathrm{L}} \cos \left(\omega_{L} t+\varphi_{L}\right)-\mathrm{A}_{\mathrm{H}} \cos \left(\omega_{H} t+\varphi_{H}\right)\right\}
\end{aligned}
$$

where $A_{L}$ and $A_{H}$ are the magnitudes of the driver- and driventranslators, respectively, and $\varphi$ is the initial phase angle. If, the mass and spring constant are chosen such that, $\omega_{L}=2$ and $\omega_{H}$ $=2 \sqrt{2}$, the simulation results of the vertical positions of the translators from their initial positions are shown in Fig. 3.

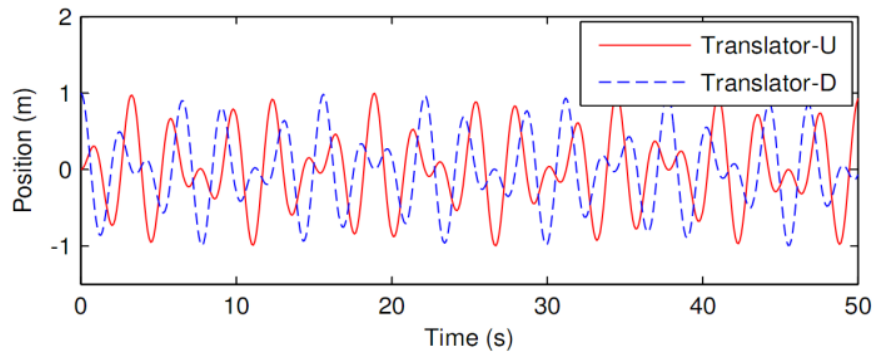

Fig. 3. Vertical displacement of the driver-translator (Translator-U) and driven-translator (Translator-D) for particular values of $\omega$.

The vertical motion of the driver- and driven-translators significantly varies for different values of $\omega_{L}$ and $\omega_{H}$. Figs. 46 plot the vertical positions, velocities, and speeds of the driver-translator (Translator-U) and the driven-translator (Translator-D) for $\omega_{L}=2$ and $\omega_{H}=2.2$, respectively.

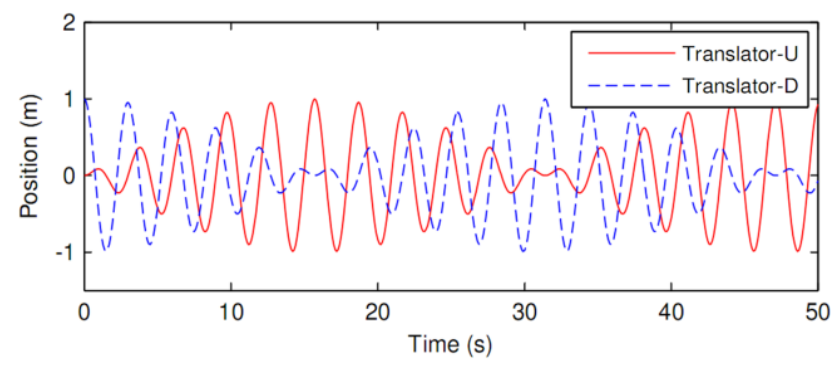

Fig. 4. Vertical displacement of the translators for $\omega_{L}=2$ and $\omega_{H}=2.2$. 


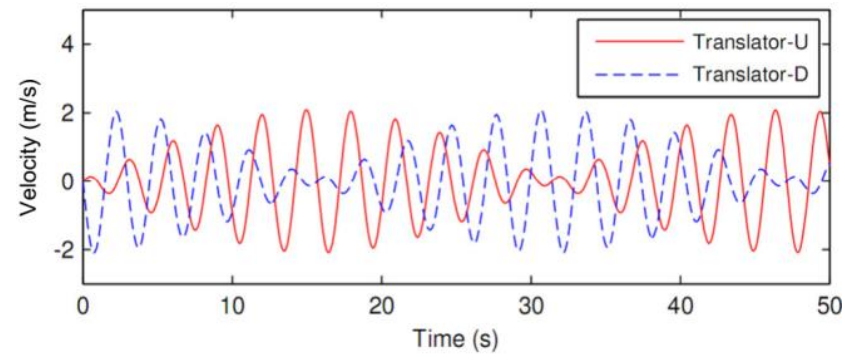

Fig. 5. Vertical velocity of the translators for $\omega_{L}=2$ and $\omega_{H}=2.2$.

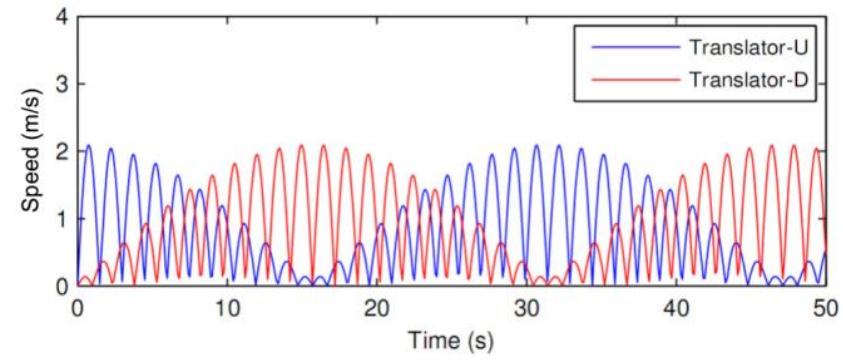

Fig. 6. Vertical speed of the translators for $\omega_{L}=2$ and $\omega_{H}=2.2$.

According to Fig. 6, the basic advantage of this proposed translator system for a wide time-span is that the speed of at least one of the translators is non-zero, which ensures much electrical power generation. As the translator is connected to the buoy, the mathematical model of the buoy also needs to be considered. The buoy force, $F_{\text {buoy }}$ can be expressed in the following.

$$
\begin{gathered}
\frac{d^{2} z_{\text {buoy }}}{d t^{2}}=a_{\text {buoy }}=\frac{d v_{\text {buoy }}}{d t} \\
F_{\text {buoy }}(t)=\rho g \pi r_{\text {buoy }}{ }^{2}\left[z_{\text {buoy }}-z_{\text {wave }}(t)\right] \\
+\left(R_{\text {rad }}+R_{\text {vis }}\right)\left[v_{\text {buoy }}-v_{\text {wave }}(t)\right]
\end{gathered}
$$

where $z_{\text {buoy }}$ is the vertical displacement, $v_{\text {buoy }}$ the vertical velocity, $a_{\text {buoy }}$ the vertical acceleration of the cylindrical buoy, $r_{\text {buoy }}$ the radius of the buoy, $g$ the gravitational acceleration, $R_{\text {rad }}$ the radiation resistance, $R_{v i s}$ the viscous resistance, $\rho$ the mass density, $z_{\text {wave }}$ the vertical displacement, $v_{\text {wave }}$ the vertical velocity of the oceanic water. Therefore, the acceleration of the buoy, $a_{\text {buoy }}$ transferred to the translator of the proposed DPLEG can be represented as follows.

$$
a_{\text {buoy }}=\frac{F_{\text {buoy }}(t)}{M_{\text {tr }}+M_{\text {buoy }}+M_{\text {water }}}
$$

where $M_{t r}$ is the mass of the translator, $M_{\text {buoy }}$ the mass of the buoy, and $M_{\text {water }}$ the added mass due to the oceanic water.

\section{Construction of the Proposed DPLEG}

Fig. 7(a) illustrates the isometric and Fig. 7(b) shows the top view of an individual segment of the proposed DPLEG which contains 10 windings. Each of the winding consists of a pair of coils in series, which is able to generate electrical power of $50 \mathrm{~W}$. Therefore, the power rating of this single segment is $500 \mathrm{~W}$. The DPLEG is composed of two identical segments: the driver-and driven-linear generators.

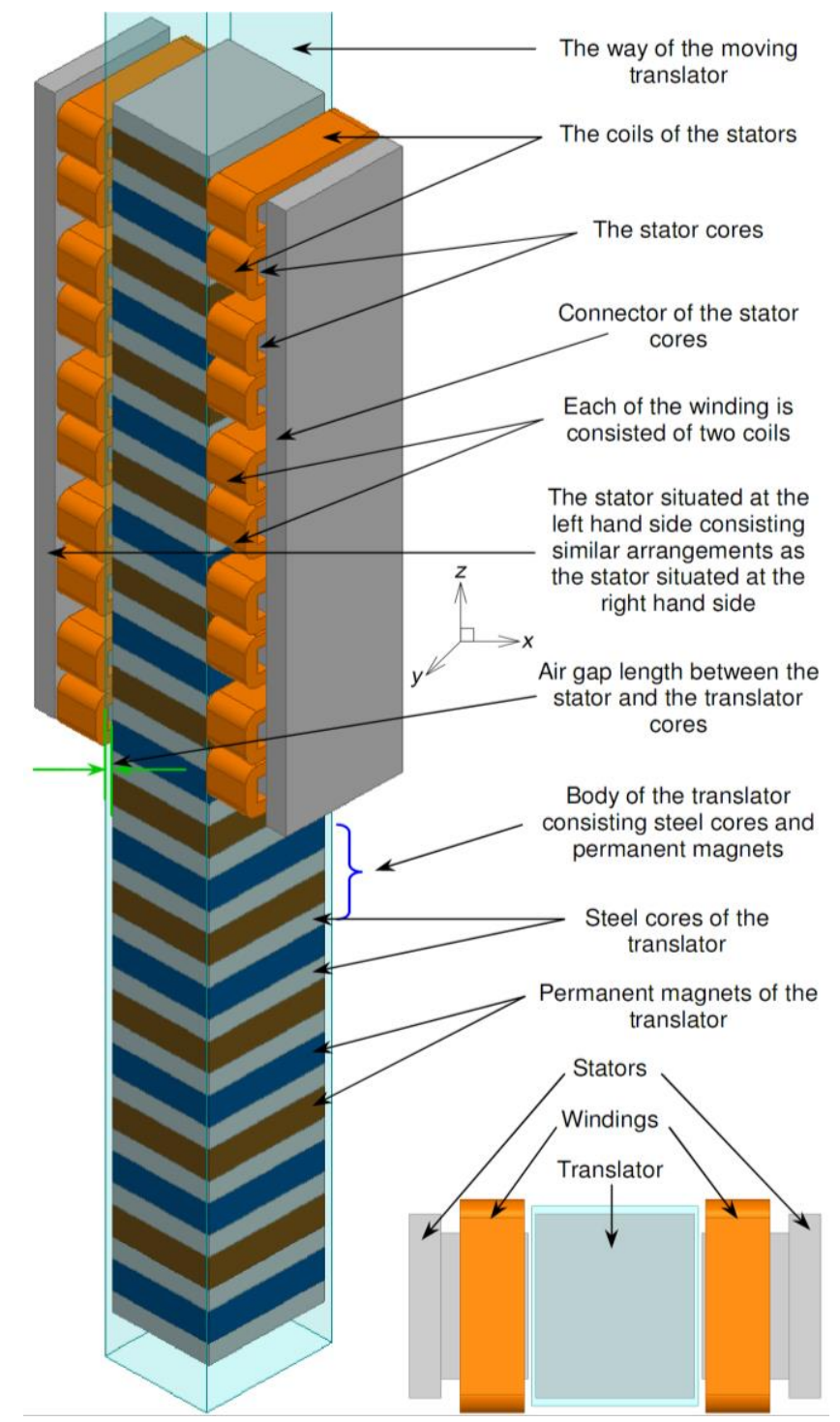

(a)

(b)

Fig. 7. (a) The construction of one of the identical segments of the proposed DPLEG. (b) Top view of the DPLEG.

The stators are identical and fixed with the enclosure. The driver- and driven-translators are also identical. They are connected to each other with a mechanical spring. The length of each spring needs to be matched with the stroke length of the translator. Then the spring constant depends on the stroke length, the mass of the translator and the vertical mechanical force created by the oceanic wave to the buoy/float. The number of slots/pole/phase is four and the winding factor is 0.65 . The purpose of the stator core connector is to connect one individual segment to another one, which is not shown in Fig. 7(a). This mechanism can improve the physical strength and robustness of this DPLEG. Ordinary mild steel core is used in the proposed design. 
The neodymium iron boron $(\mathrm{NdFeB})$ permanent magnets are used in the translator with a remanence magnetic flux density of $1.1 \mathrm{~T}$ and a coercive force of $-837,000 \mathrm{~A} / \mathrm{m}$. Fig. 8 shows model of the proposed DPLEG where $E_{\text {driver }}$ is the generated voltage of the driver-generator, $E_{\text {driven }}$ the generated voltage of the driven-generator, $L_{\text {winding }}$ the equivalent series inductance of the winding, $R_{\text {winding }}$ the winding resistance, $L_{f}$ the filtering inductance, $C_{f}$ the filtering capacitance, and $R_{\text {load }}$ the load resistance. The dotted lines around the LC filter and $R_{\text {load }}$ indicate the dc bus to which other DPLEGs can also be connected.

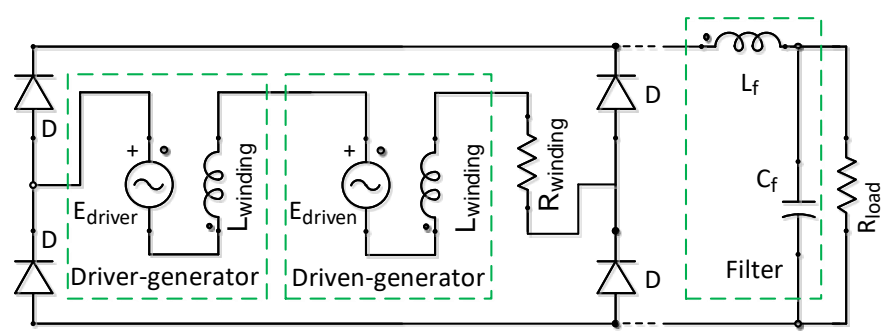

Fig. 8. Equivalent circuit diagram of the DPLEG with load.

\section{Stator TOOth Shape Optimization of the DPLEG}

The simulation shows that, the stator tooth shape has the effect on power generation of a linear generator. Further analysis shows that, using this concept the performance enhancement of a linear generator is possible. To achieve this, the steps can be summerized as: (i) determination of the PM size along with thickness of stator teeth, (ii) selection of the factors $a$ and $b$ as shown in Fig. 9, (iii) selection of the proper curvature as shown in Fig. 10.

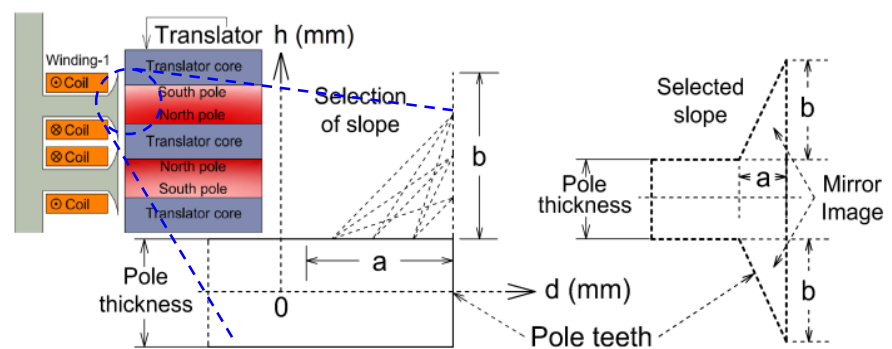

(a)

(b)
Fig. 9. Selection of the parameters a and b. (a) Determination of the slope by pole tooth points and (b) selected parameters $a$ and $b$.

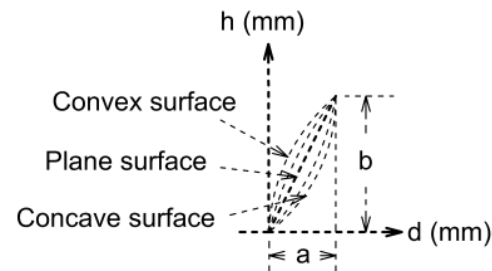

(a)

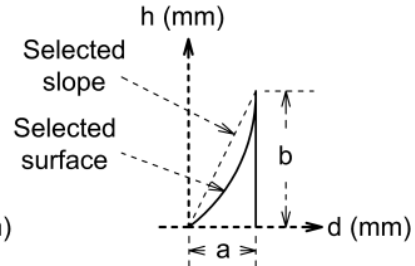

(b)
Fig. 10. (a) Determination of surface and (b) selected surface with points a and $b$.

Simplified expression of the curvature is $e^{k x}-1$ or $u\left(1-e^{-k x}\right)$, where the degree of curved surface is expressed by $k$ and $u$ a variable. The voltage generated by the DPLEG, can be expressed in the following:

$$
E_{g}(t)=K_{g} \cos \left(\frac{\pi}{\tau_{p}} z_{t r}+i \frac{2 \pi}{n}\right) v_{t r}(t)
$$

where $E_{g}$ is the generated voltage, $i=-2,-1,0,1,2 ; n=5, K_{g}$ a constant related to the construction of the machine, $z_{t r}$ the vertical displacement, $\tau_{p}$ the pole pitch, and $v_{t r}$ the velocity of the translator.

As the finite element method has been used to determine the electromagnetic field and to calculate the applied force, a proper mesh setup is important for obtaining accurate results. In the proposed design, two types of stator tooth shapes are simulated. One has flat plane surfaces only, and the other has curved surfaces. The finite element mesh is basically a tetrahedra which have faceted or meshed surfaces. The surfaces of the plane tooth shapes match exactly the meshed surfaces, while the actual surfaces of the curved tooth shapes closely match the meshed surfaces maintaining a distance which is known as a surface deviation. The accuracy of the simulaton results depends on this deviation that can be minimized by increasing the mesh density.

On the other hand, a mesh of excessively high density would slow down the simulation process. Since the above method is iterative, it will be time consuming; and it is possible that the method can fail to converge. Fig. 11 illustrates a new method that has been used to create a proper mesh setup to achieve better results as well as to save simulation time. Fig. 11 also depicts the genetic algorithm for the optimization of the stator tooth shape. The optimization process shown in Fig. 11, further increases electrical power generation and minimizes force ripples.

The force ripples are calculated from the applied force to the translator where the force can be expressed as:

$$
F_{t r}=F_{\text {em }}+F_{\text {load }}=m_{t r} a_{t r}+\lambda v_{t r}
$$

where $F_{t r}$ is the total force of the translator, $F_{e m}$ the electromagnetic force, $F_{\text {load }}$ the external load force, $\lambda$ the damping, $a_{t r}$ the acceleration, $m_{t r}$ the translator mass, and $v_{t r}$ the velocity of the translator. If, $W$ is the magnetic co-energy of the system, $\vec{B}$ the magnetic flux density, $H$ the magnetic field intensity, the suffix $l l$ and $u l$ represent the lower and the upper limit of the moving object, respectively. The force on any part/object, $F_{\text {object }}$ of the translator in the moving direction at a distance, $l$ can be expressed in the following

$$
\begin{aligned}
& F_{\text {object }}=\frac{d}{d l}\left\{W\left(l, i_{a}\right)\right\} \mid \text { for constant } i_{a} \\
& =\frac{\partial}{\partial l}\left[\int_{y=x_{l l}}^{y_{u l}} \int_{x=y_{l l}}^{x_{u l}} \int_{z=z_{l l}}^{z_{u l}}\left\{\int_{0}^{H} \vec{B} \cdot d H\right\} d x d y d z\right]
\end{aligned}
$$






Fig. 11. Proposed algorithm for the graphical optimization of the stator poles.

The $x, y$, and $z$ axes of the proposed DPLEG are represented in a 3D Cartesian coordinate system as shown in Fig. 7(a). The oscillation of the translator force is related to the current and the magnetic field. The instantaneous virtual force, $F_{\text {virtual }}$ on the translator can be expressed as follows:

$$
F_{\text {virtual }}=\frac{1}{2}\left[\int \operatorname{Re}|\vec{J} \times \vec{B}| d v+\int \operatorname{Re}\left|\vec{J} \times \overrightarrow{B_{\theta}}\right| d v\right]
$$

where $\vec{J}$ is the conduction current density, $\overrightarrow{B_{\theta}}$ the flux density at a perticular time, $\theta=\omega t$, and $\omega$ the angluar velocity. The selected curvature of the stator pole tooth can be approximated by exponentials or polynomials as follows

$$
h=f(d)=C_{1} d^{4}+C_{2} d^{3}+C_{3} d^{2}+C_{4} d+C_{5}
$$

where $C_{1}, C_{2}, \ldots C_{5}$ are the coefficients of the polynomial of a single indeterminate $d$ and $h$ is the height of stator teeth edge.

\section{Simulation REsults}

In the simulation setup, the translator moves vertically at the velocity of $1 \mathrm{~m} / \mathrm{s}$ with respect to its stators maintaining 2 $\mathrm{mm}$ air gap. Fig. 12 shows the magnetic flux intensity, $H$, flux density, $B$, flux lines, $A$, and air gap field in the DPLEG without and with the optimization of stator tooth shape. Fig. 13 illustrates the effects of using different LC filters after rectification. A selection of proper inductance and capacitance is required to avoid overshoot and to get proper filtered output. They are finally chosen as $25 \mathrm{mH}$ and $2 \mathrm{mF}$, respectively. The voltage, current, and power are plotted in Fig. 14 for the selected LC filter. Comparing Figs. 13 and 14, the effects of filtering can be observed as the ripples are significantly minimized.

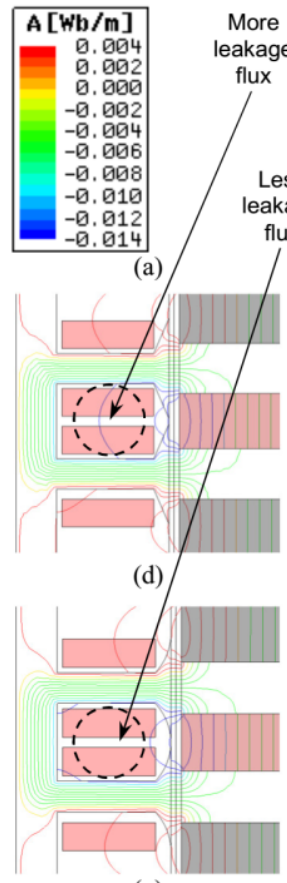

(g)

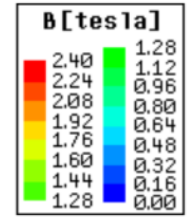

(b)

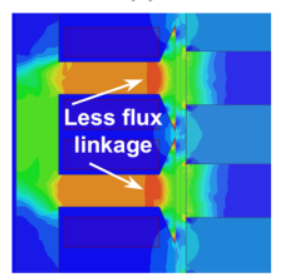

(e)

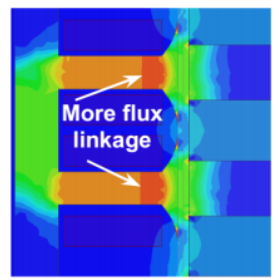

(h)

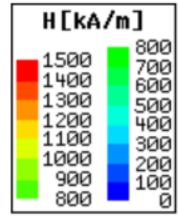

(c)

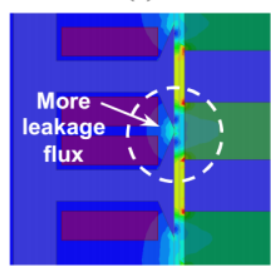

(f)

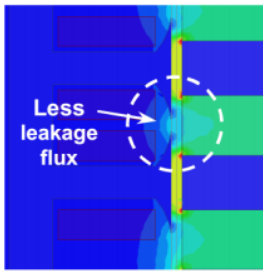

(i)
Fig. 12. (a) Scale of magnetic flux lines, (b) density and (c) intensity. (d) Flux lines, (e) density, and (f) intensity of the DPLEG without curvature optimization and slope optimization. (g) Flux lines, (h) density, and (i) intensity of the DPLEG with both the curvature and slope optimization.

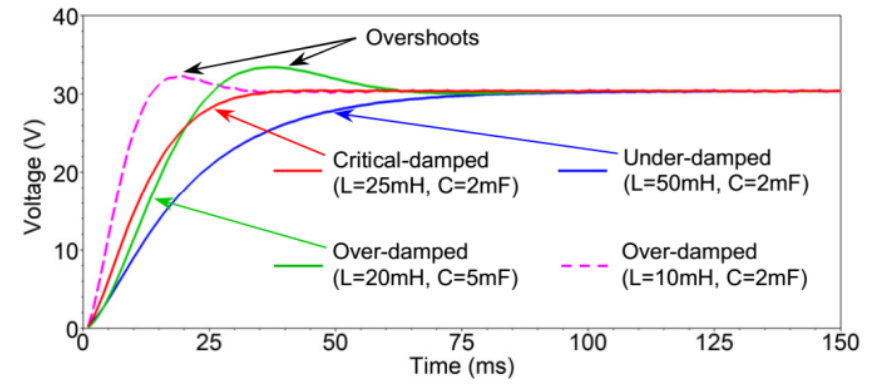

Fig. 13. Generated voltages of the DPLEG for different filtering inductances and capacitances.

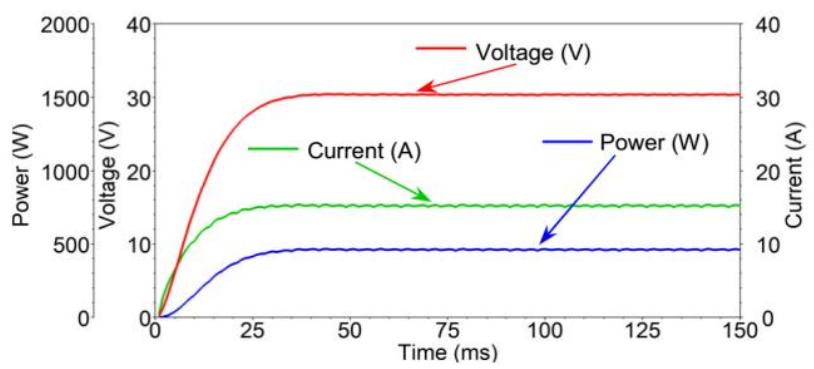

Fig. 14. Voltage, current, and power of the DPLEG after filtering. 
The required applied forces on the translator of DPLEG with and without optimization are shown in Fig. 15. Fig. 16 shows the core loss profile of the proposed DPLEG with and without optimization. The force ripples and the core loss components are low for the optimized DPLEG. Fig. 17 shows the original curved face of the proposed tooth and its approximation. The dimensions of the proposed DPLEG are tabulated in Table I. Table II shows the comparisons of the results for different stator tooth shapes defined by $a, b$, and straight/curved faces. It also shows that the force ripples are minimized successfully by optimized stator tooth shape.

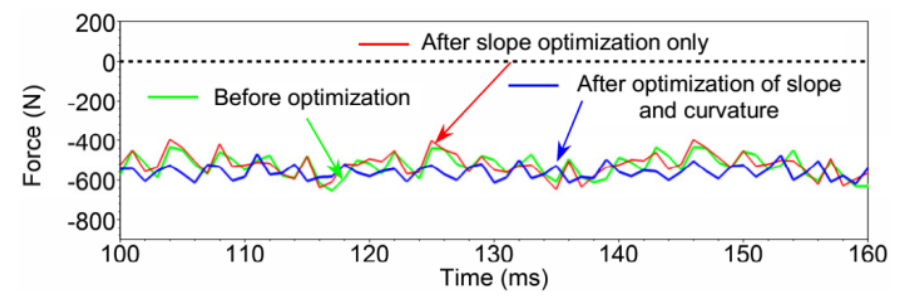

Fig. 15. Applied force to the DPLEG with and without optimization.

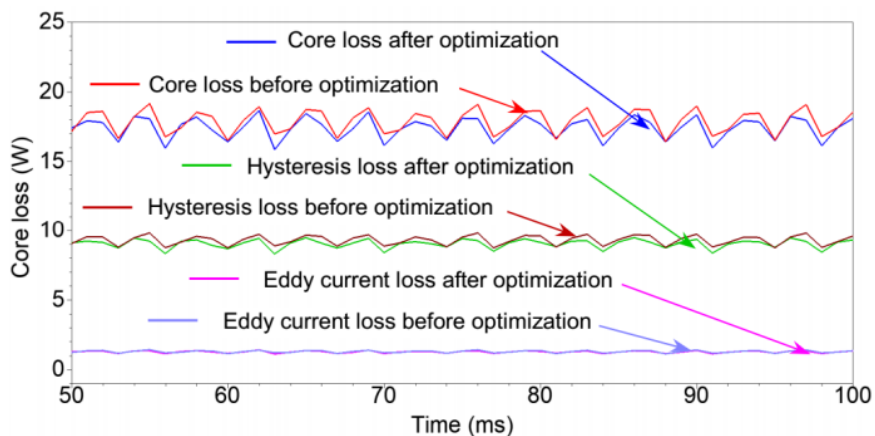

Fig. 16. Core losses of the proposed DPLEG with and without optimization.

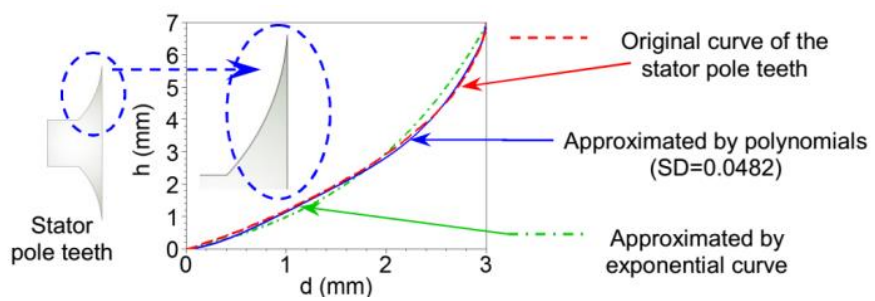

Fig. 17. Selected curvature of the stator pole teeth.

A downscale prototype and oceanic wave motion simulator are constructed in the laboratory. The experimental results are found to be promising for DPLEG when compared with that of the SPLEG topology. The prototype of the proposed DPLEG with its different components are presented in Fig. 18. The stroke length, time period, and maximum power rating of the DPLEG are around $0.36 \mathrm{~m}, 1.5 \mathrm{~s}$, and $100 \mathrm{~W}$, respectively. The dimensions of the proposed DPLEG prototype are shown in Table III. The unique advantage of the proposed DPLEG is illustrated in Fig. 19 where it is shown that the driven generator generates adiquate voltage at the moment of zero vertical velocity of the oceanic wave. The comparison of the generated voltages of the DPLEG obtained from the experiment and simulation are shown in Fig. 20 where the voltage per division is $20 \mathrm{volt} / \mathrm{div}$ and time per division is 20 $\mathrm{ms} / \mathrm{div}$ for both the simulation and experimental plots.
TABLE I

DIMENSIONS OF THE PROPOSED DPLEG

\begin{tabular}{lc}
\hline \hline Name of the items & Value \\
\hline Thickness of the stator pole $(\mathrm{mm})$ & 6 \\
Width of the stator pole shoe $(\mathrm{mm})$ & 3 \\
Length of the stator pole shoe $(\mathrm{mm})$ & 7 \\
Thickness of the permanent magnet (mm) & 11 \\
Vertical distance of the stator poles of the same winding $(\mathrm{mm})$ & 21 \\
Thickness of the translator core (mm) & 10 \\
Vertical distance of the stator poles of the same side $(\mathrm{mm})$ & 28 \\
Vertical distance of the translator for one cycle $(\mathrm{mm})$ & 42 \\
Height of the stator pole shoe (mm) & 20 \\
Length of the cross section of the copper coil $(\mathrm{mm})$ & 6 \\
Air gap between the stator pole shoe tips (mm) & 1 \\
Width of the cross section of the copper coil (mm) & 18 \\
Total width of the stator poles (mm) & 22 \\
Width of the stator poles (mm) & 19 \\
Vertical distance between two consecutive stator poles $(\mathrm{mm})$ & 25 \\
Width of the stator core connector (mm) & 8 \\
\hline \hline
\end{tabular}

TABLE II

COMPARISONS OF DifFERENT STATOR TEETH EFFECT IN THE SAME DPLEG

\begin{tabular}{lcccc}
\hline \hline Name of the items & $\begin{array}{c}\text { Value }(\mathrm{mm}) \\
\mathrm{a}=0, \mathrm{~b}=0\end{array}$ & $\begin{array}{c}\text { Value }(\mathrm{mm}) \\
\mathrm{a}=2, \mathrm{~b}=4\left(\mathrm{~s}^{*}\right)\end{array}$ & $\begin{array}{c}\text { Value }(\mathrm{mm}) \\
\mathrm{a}=3, \mathrm{~b}=7(\mathrm{~s})\end{array}$ & $\begin{array}{c}\text { Value }(\mathrm{mm}) \\
\mathrm{a}=3, \mathrm{~b}=7\left(\mathrm{c}^{*}\right)\end{array}$ \\
\hline Generated power $(\mathrm{W})$ & 445.4 & 443.1 & 441.6 & 463.38 \\
Ripple of the de power & 13.56 & 10.14 & 10.12 & 12.53 \\
Force ripples & -10.96 & -12.15 & -12.54 & -6.4 \\
Maximum value of $B(\mathrm{~T})$ & 2.8239 & 2.6719 & 2.76 & 2.8648 \\
SD $^{* *}$ of force & 57.005 & 63.87 & 64.635 & 33.697 \\
\hline \hline
\end{tabular}

$\overline{\text { N.B: } \text { SD }^{* *} \text { means standard deviation, } \mathrm{s}^{*} \text { means straight face, } \mathrm{c}^{*} \text { means curvature }}$

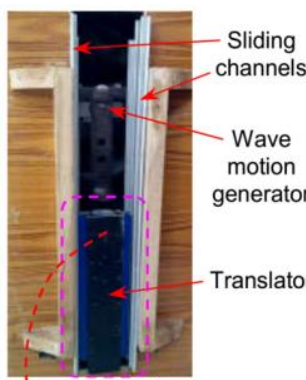

(a)

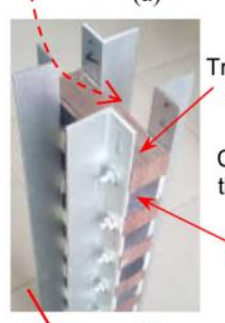

(d)



(g)

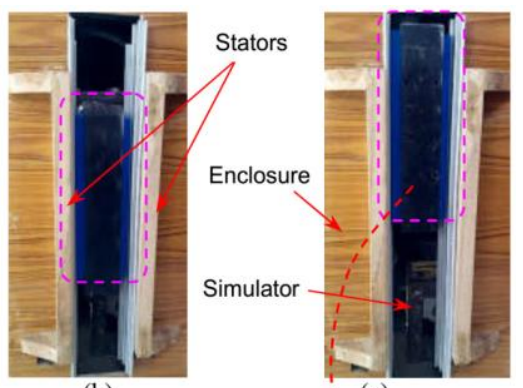

(b)

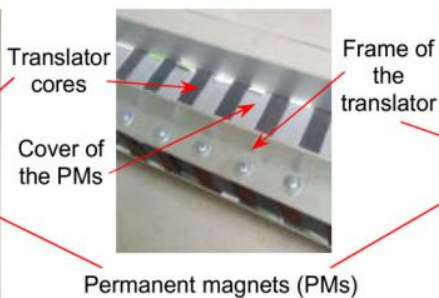

(e)

(c)

lower end
Fig. 18. Prototype of the proposed DPLEG. Translator at the (a) lower (b) middle, and (c) upper position. (d) The driver-translator, (e) translator components, (f) driven-translator, and (g) combined form after assembling. 


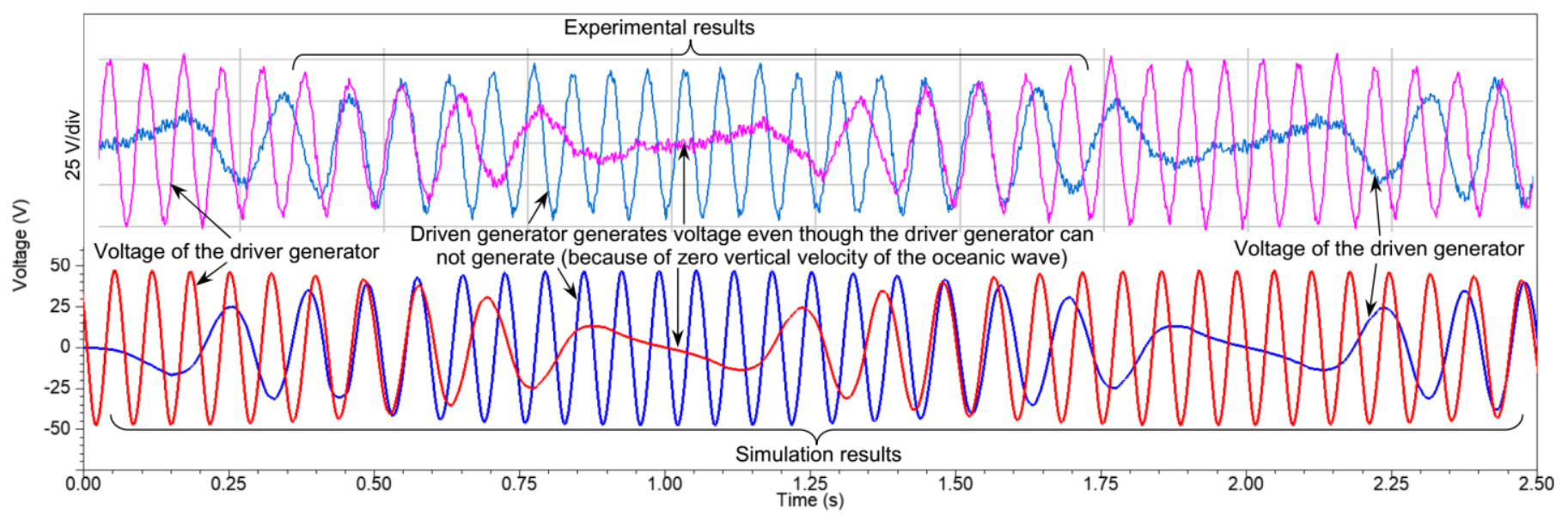

Fig. 19. Simulated and experimental results of the generated voltages of the driver- and driven-generator for comparison.

TABLE III

DIMENSIONS OF THE PROPOSED PROTOTYPE

\begin{tabular}{lc}
\hline \hline Name of the items & Value \\
\hline Air gap length between the stator and translator $(\mathrm{mm})$ & 2 \\
Height of the stator pole shoe $(\mathrm{mm})$ & 20 \\
Width of the prototype $(\mathrm{mm})$ & 106 \\
Height of the prototype $(\mathrm{mm})$ & 432 \\
Total width of the stator poles $(\mathrm{mm})$ & 24 \\
Space (width) inside the bobbin for the copper winding $(\mathrm{mm})$ & 18 \\
\hline \hline
\end{tabular}

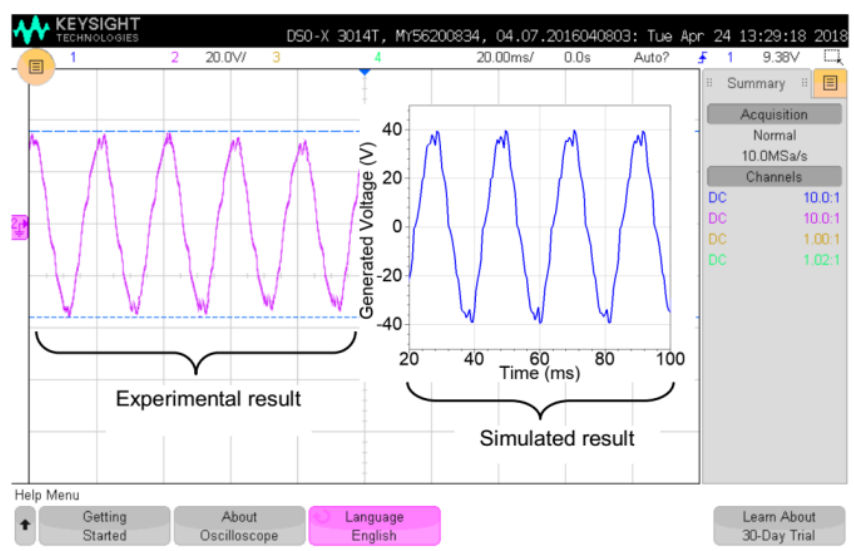

Fig. 20. Experimental terminal voltage of the generator compared with the simulation result.

The experimental results from the $100 \mathrm{~W}$ laboratory prototype of the proposed dual-port linear electric generator, shown in Fig. 19, verify the unique advantage of the DPLEG. The electrical power, $P_{d c}$ is measured at the dc bus as shown in Fig. 8 using $P_{d c}=V_{d c} \times I_{d c}$ where $V_{d c}$ is dc bus voltage and $I_{d c}$ is line current. On the other hand, the mechanical power, $P_{m}$ is found using $P_{m}=F_{t r} \times v_{t r}$ where $F_{t r}$ is the applied mechanical force on the translator and $v_{t r}$ is the translator velocity. Therefore, the efficiency, $\eta=P_{d c} / P_{m}$.

In contrust to the DPLEG, this feature cannot be achieved using the traditional SPLEG which supplies discontinuous power due to its working principle and the intermittent nature of the oceanic waves. The voltage ripples obtained from the experimental and simulated results for different filter inductances and capacitances are shown in Fig. 21 where 20 volt/div and $20 \mathrm{~ms} / \mathrm{div}$ are used for volt and time per division, respectively.

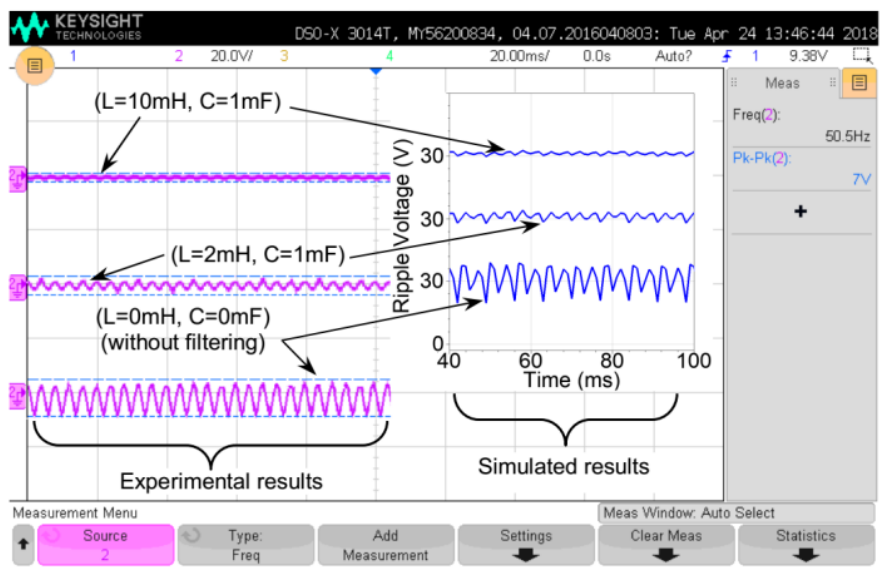

Fig. 21. Experimental rectified output voltages with different filters and comparison with the simulated results.

The sampling rate of the digital oscilloscope is $10 \mathrm{Ms} / \mathrm{s}$ (mega samples/second) whereas, the step size is $1 \mathrm{~ms}(1000$ $\mathrm{s} / \mathrm{s}$ ) in the simulation setup. Therefore, some differences between the simulation and the experimental results are observed.

\section{CONCLUSION}

The analysis and simulation results show that the proposed DPLEG is able to generate adequate electrical power even at the moment of zero translator velocity, which is a unique property. The proposed optimization method applied on the DPLEG by optimizing the curvature, size and slope of the stator tooth effectively reduces the force ripples. It also generates $17.98 \mathrm{~W}$ more electrical power compared to that of the DPLEG without optimization. The full load efficiency of the DPLEG is maintained approximately $83.92 \%$. The proposed design method used for the DPLEG with the optimization of the stator tooth shape is also applicable to other types of linear generators. An advantage of the proposed design method used for the DPLEG is that, by using the upper and lower mechanical springs, the upper and lower end 
stoppers do not need to be mounted to prevent the bumping between the translator and the main enclosure of the generator. The simulation and experimental results demonstrate the excellent features of the DPLEG while considering the electromagnetic constraints. The waveforms obtained from the experimental and simulated results are close to each other.

\section{REFERENCES}

[1] Y. Hong, R. Waters, C. Boström, M. Eriksson, J. Engström, and M. Leijon, "Review on electrical control strategies for wave energy converting systems," Renew. Sustain. Energy Rev., vol. 31, pp. 329-342, 2014.

[2] S. Ademi, M. G. Jovanović, and M. Hasan, "Control of brushless doubly-fed reluctance generators for wind energy conversion systems," IEEE Trans. Energy Convers., vol. 30, no. 2, pp. 596-604, Jun. 2015.

[3] M. G. Jovanović, R. E. Betz and Jian Yu, "The use of doubly fed reluctance machines for large pumps and wind turbines," IEEE Trans. Ind. Appl., vol. 38, no. 6, pp. 1508-1516, Nov./Dec. 2002.

[4] G. Buja and R. Menis, "Dependability and functional safety: Applications in industrial electronics systems," IEEE Ind. Electron. Magazine, vol. 6, no. 3, pp. 4-12, Sep. 2012.

[5] B. Robertson, C. Hiles, E. Luczko, and B. Buckham, "Quantifying wave power and wave energy converter array production potential," Int. J. Mar. Energy, vol. 14, pp. 143-160, 2015.

[6] R. Vermaak and M. J. Kamper, "Design aspects of a novel topology aircored permanent magnet linear generator for direct drive wave energy converters," IEEE Trans. Ind. Electron., vol. 59, no. 5, pp. 2104-2115, 2012.

[7] X. Xiao, X. Huang, and Q. Kang, "A hill-climbing-method-based maximum-power-point-tracking strategy for direct-drive wave energy converters," IEEE Trans. Ind. Electron., vol. 63, no. 1, pp. 257-267, 2016.

[8] Yi Du, Ming Cheng, and K. T. Chau, "Simulation of the linear primary permanent magnet Vernier machine system for wave energy conversion," in 20th Int. Conf. Electr. Mach. Syst., Busan, 2013, pp. 262-266.

[9] M. Alberdi, M. Amundarain, A. J. Garrido, I. Garrido, O. Casquero, and M. De-la-Sen, "Complementary control of oscillating water columnbased wave energy conversion plants to improve the instantaneous power output," IEEE Trans. Energy Convers., vol. 26, no. 4, pp. 10211032, Dec. 2011.

[10] O. Farrok, M. R. Islam, M. R. I. Sheikh, Y. Guo, and J. Zhu, "Design and analysis of a novel lightweight translator permanent magnet linear generator for oceanic wave energy conversion," IEEE Trans. Magn., vol. 53, no. 11, art. 8207304, Nov. 2017.

[11] O. Keysan, M. Mueller, A. McDonald, N. Hodgins, and J. Shek, "Designing the C-GEN lightweight direct drive generator for wave and tidal energy," IET Renew. Power Gener, vol. 6, no. 3, p. 161, 2012.

[12] J. Prudell, M. Stoddard, E. Amon, T. K. A. Brekken, and A. Von Jouanne, "A permanent-magnet tubular linear generator for ocean wave energy conversion," IEEE Trans. Ind. Appl., vol. 46, no. 6, pp. 2392$2400,2010$.

[13] O. Farrok, M. R. Islam, M. R. I. Sheikh, Y. Guo, J. Zhu, and Gang Lei, "Oceanic wave energy conversion by a novel permanent magnet linear generator capable of preventing demagnetization," IEEE Trans. Ind. Appl., vol. 54, no. 6, pp. 6005-6014, Nov.-Dec. 2018.

[14] S. Zhu, M. Cheng, W. Hua, X. Cai, and M. Tong, "Finite element analysis of flux-switching PM machine considering oversaturation and irreversible demagnetization," IEEE Trans. Magn., vol. 51, no. 11, pp. 1-4, Nov. 2015.

[15] O. Farrok and M. R. Islam, "Advanced electrical machines for oceanic wave energy conversion," Chapter-4, Springer, pp. 115-141, Jan. 2018. DOI: 10.1007/978-981-10-7287-1_4.

[16] I. Stamenkovic, N. Milivojevic, N. Schofield, M. Krishnamurthy, and A. Emadi, "Design, analysis, and optimization of ironless stator permanent magnet machines," IEEE Trans. Power Electron., vol. 28, no. 5, pp. 2527-2538, May 2013.

[17] A. Pirisi et al., "Optimization of an energy harvesting buoy for coral reef monitoring," in Proc. IEEE CEC, 2013, pp. 629-634.

[18] Y. Li, T. Qu, C. Gu, Y. Jiang, Y. Yang, W. Yuan, R. Liu, and Z. Han,
"Design and optimization of high-temperature superconducting racetrack magnet for the rotor of a $100-\mathrm{kW}$ generator," IEEE Trans. Appl. Supercond., vol. 25, no. 3, Jun. 2015.

[19] O. Farrok, M. R. Islam, M. R. I. Sheikh, and W. Xu, "A new optimization methodology of the linear generator for wave energy conversion systems," in IEEE Int. Conf. Ind. Techn., Taipei, Taiwan, Mar. 14-17, 2016, pp. 1412-1417.

[20] O. Farrok, M. R. Islam, Y. Guo, J. Zhu and W. Xu, "A novel design procedure for designing linear generators," IEEE Trans. Ind. Electron., vol. 62, no. 2, pp. 1846-1854, Feb. 2018.

[21] N. Bianchi, S. Bolognani, D. Corte, and F. Tonel, "Tubular linear permanent magnets motors: An overall comparison," IEEE Trans. Ind. Appl., vol. 39, no. 2, pp. 466-475, Mar./Apr. 2003.

[22] B. L. J. Gysen, K. J. Meessen, J. J. H. Paulides, and E. A. Lomonova, "3-D analytical and numerical modeling of tubular actuators with skewed permanent magnets," IEEE Trans. Magn., vol. 47, no. 9, pp. 2200-2212, 2011.

[23] C. T. Liu, C. L. Lin, and C. C. Hwang, "Compact model of a slot-less tubular linear generator for renewable energy performance assessments," IEEE Trans. Magn., vol. 46, no. 6, pp. 1467-1470, Jun. 2010.

[24] D. Žarko1, D. Ban, and T. A. Lipo, "Analytical calculation of magnetic field distribution in the slotted air gap of a surface permanent magnet motor using complex relative air-gap permeance," IEEE Trans. Magn., vol. 42, no. 7, pp. 1828-1837, Jul. 2007.

[25] N. P. Gargov and A. F. Zobaa, "Multi-phase air-cored tubular permanent magnet linear generator for wave energy converters," IET Renew. Power Gener., vol. 6, no. 3, pp. 171-176, 2012.

[26] H. Zhang, Z. Nie, X. Xiao, R. Aggarwal, Q. Kang, M. Ainslie, J. Zhu, T. Coombs, and W. Yuan, "Design and simulation of SMES system using YBCO tapes for direct drive wave energy converters," IEEE Trans. Appl. Supercond., vol. 23, no. 3, art. 5700704, Jun. 2013.

[27] M. Alberdi, M. Amundarain, A. J. Garrido, I. Garrido and F. J. Maseda, "Fault-ride-through capability of oscillating-water-column-based wavepower-generation plants equipped with doubly fed induction generator and airflow control," IEEE Trans. Ind. Electron., vol. 58, no. 5, pp. 1501-1517, May 2011.

[28] E. Tedeschi and M. Molinas, "Tunable control strategy for wave energy converters with limited power takeoff rating," IEEE Trans. Ind. Electron., vol. 59, no. 10, pp. 3838-3846, Oct. 2012.

[29] O. Farrok, M. R. Islam, M. R. I. Sheikh, Y. Guo, and J. Zhu, "A split translator secondary stator permanent magnet linear generator for oceanic wave energy conversion," IEEE Trans. Ind. Electron., vol. 65, no. 9, pp. 7600-7609, Sep. 2018.

[30] J. Engström, V. Kurupath, J. Isberg, and M. Leijon, "A resonant two body system for a point absorbing wave energy converter with directdriven linear generator," J. Appl. Phys., vol. 110, no. 12, pp. 1-8, Dec. 2011.

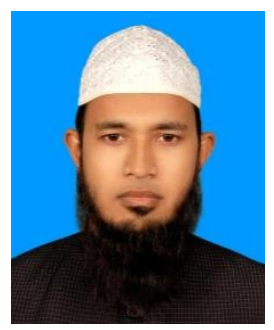

Omar Farrok (M'17) received the B.Sc., M.Sc., and Ph.D. degree from Rajshahi University of Engineering and Technology (RUET), Rajshahi-6204, Bangladesh, in 2006, 2009, and 2016, respectively, all in the department of Electrical and Electronic Engineering (EEE). He is currently a distinct Associate Professor (Since 2016) in the department of EEE, Ahsanullah University of Science and Technology (AUST), Dhaka-1208, Bangladesh. He joined as a Lecturer in 2007 in the same department at AUST. He has also been registered by the board of Bangladesh Professional Engineers Registration Board (BPERB) as a Professional Engineer (P.Eng.) in 2017.

$\mathrm{He}$ has authored and coauthored more than 40 technical papers in international journals and conference proceedings. His research interests include renewable energy systems, oceanic wave energy converters, electrical machines and drives, magnetic properties of materials, electromagnetics, and power electronics.

Dr. Farrok achieved the best paper award in ICEMS-2017, Sydney, Australia on 11-14 August 2017. 


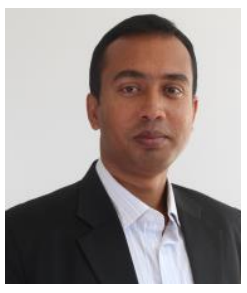

Md. Rabiul Islam (M'14-SM'16) received the B.Sc. and M.Sc. degree from Rajshahi University of Engineering and Technology (RUET), Rajshahi, Bangladesh, in 2003 and 2009, respectively; and the Ph.D. degree from University of Technology Sydney (UTS), Sydney, Australia, in 2014, all in electrical engineering.

He was appointed a lecturer at RUET in 2005 and promoted to full professor in 2017. In early 2018, he joined at the School of Electrical, Computer, and Telecommunications Engineering (SECTE), University of Wollongong (UOW), Wollongong, Australia. He is also a member of Australian Power Quality and Reliability Center of UOW. His research interests are in the fields of power electronic converters, renewable energy technologies, power quality, electrical machines, electric vehicles, and smart grid.

He has authored or co-authored 130 papers in international journals and conference proceedings. He has served as a Guest Editor for IEEE Transactions on Energy Conversion and IEEE Transactions on Applied superconductivity. Currently he is editing a special issue for IET Electric Power Applications.

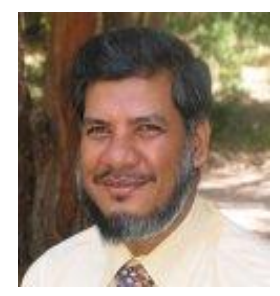

Kashem M Muttaqi (M'01, SM'05) received the B.Sc. degree in electrical and electronic engineering from Bangladesh University of Engineering and Technology (BUET), Dhaka, Bangladesh in 1993, the M.Eng.Sc. degree in electrical engineering from University of Malaya, Kuala Lumpur, Malaysia in 1996 and the Ph.D. degree in Electrical Engineering from Multimedia University, Selangor, Malaysia in 2001.

Currently, he is a Professor at the School of Electrical, Computer, and Telecommunications Engineering, and member of Australian Power Quality and Reliability (APQRC) at the University of Wollongong, Wollongong, Australia. He was associated with the University of Tasmania, Hobart, Australia as a Research Fellow/Lecturer/Senior Lecturer from 2002 to 2007, and with the Queensland University of Technology, Brisbane, Australia as a Research Fellow from 2000 to 2002. Previously, he also worked for Multimedia University as a Lecturer for three years.

He has authored or coauthored 285 papers in international journals and conference proceedings. His research interests include distributed generation, renewable energy, electrical vehicles, smart-grid, power system planning and emergency control.

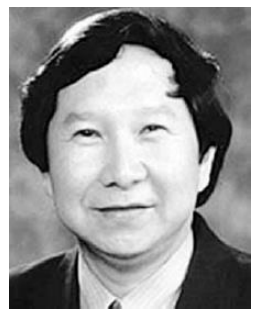

Danny Sutanto (SM'89) received the B.Eng. (Hons.) and Ph.D. degrees from the University of Western Australia, Perth, W.A., Australia, in 1978 and 1981, respectively. He is currently a Professor of power engineering with the University of Wollongong, Wollongong, N.S.W., Australia. His research interests include power system planning, power system emergency, analysis and harmonics, flexible alternating current transmission system, and battery energy storage systems.

He was the IEEE Industry Applications Society Area Chair for Region 10 (Asia Pacific) from 2014 to 2017.

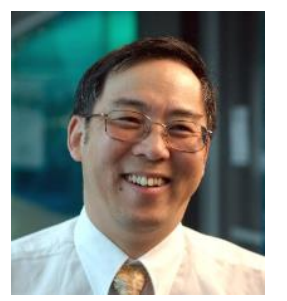

Jianguo Zhu (S'93-M'96-SM'03) received the B.E. degree in 1982 from Jiangsu Institute of Technology, Jiangsu, China, the M.E. degree in 1987 from Shanghai University of Technology, Shanghai, China, and the Ph.D. degree in 1995 from the University of Technology Sydney (UTS), Sydney, Australia, all in electrical engineering.

He was appointed a lecturer at UTS in 1994 and promoted to full professor in 2004. In 2018, he joined the University of Sydney, Australia, as a full professor and Head of School for School of Electrical and Information Engineering. His research interests include computational electromagnetics, machines and drives, power electronics, renewable energy. 